\title{
Risk of HIV among the seasonal Labour Migrants of Nepal
}

\author{
Satya Narayan Yadav* \\ communinty Medicine, Institute of medicine, Ayurveda Teaching Hospital, Kathmandu, Kathmandu, Nepal
}

\section{Objective}

The objective was to assess the risk of HIV infection among the seasonal labour migrants of Nepal.

\section{Introduction}

HIV and AIDS is not a new problem to global community and human civilization. Though much efforts had been taken yet its devastating effects can be seen in many areas like human productivity, public health, human rights etc. Nepal is experiencing a concentrated epidemic of HIV with prevalence at, or over, 5 percent in certain high-risk groups, such as intravenous drug users (IDUs), MSM, FSW, and migrant laborers in India who go to cities such as Mumbai. The possibility of transmission of HIV infection from these highrisk groups to the general population is a serious health concern. Nepal's vulnerability to HIV has increased because of several factors including poverty coupled with the lack of employment opportunities, large-scale migration and ten years of conflict. [1]

IBBS survey conducted in 2008 in mid-Terai regions reported the prevalence of HIV among seasonal migrants who had sexual contact with female sex workers in India was $2.6 \%$ [1] which indicates unsafe sex being one of the major factors of HIV transmission among the seasonal migrants. Similar study conducted among seasonal migrants reported that only $62 \%$ used condom during sex with sex worker and HIV infection was found only on those who visited Mumbai (6.1\%) and had sex with sex workers without using condom [2].

Seasonal migration for income generation in Mid-Terai part of Nepal is present since the time immemorial. People migrate to India generally to Bihar, Punjab, Uttaranchal, Maharashtra, Uttar Pradesh, Delhi states. [2]

Risk of HIV transmission among the seasonal migrants is very high. Separated from their spouses and adrift from social bindings, many to these migrants exercise unsafe sexual practices. Regular monitoring and health assistance to this population is lacking, especially in the case of those who migrate to neighboring countries like India, compared to those who receive authorized permission to work in other countries.

\section{Methods}

Analytical cross-sectional study was conducted to assess the risk of HIV among seasonal Labour migrants of three VDCs from three district of mid Terai Region of Nepal which is the transition point for seasonal migrants going to India. The study population was the male migrants of mid-Terai region visiting the study area who give oral consent and show interest to participate. 333 seasonal labor migrants' men aged between 18 to 47 years who went to India for work for at least three months and have returned home within the last three years was selected purposively.

\section{Results}

The Results found that majority of migrants were 15-25 age group which accounts for the $69.4 \%$ of the total participants and most of the respondents were found Disadvantaged dalit caste group which accounts for the $60.96 \%$ of the total participants whereas 3.9\% of participants were upper caste as well minority religious group. Majority of the participants were Hindu which accounts $84.7 \%$ and other were Muslim, Buddhist and Christian (15.3\%). About 42 percent of the participants had their sexual intercourse onset at the age less than 18 years of age. The majority of the Migrants were found to be married, i.e. 86.49 percent. Among those that had sex with women 42.68 percent ever had sex with Female sex Worker (FSW) and rest 57.33 percent had no sex with FSW in abroad It was reported that 61.25 percent ever had sex with FSW in Nepal among them those who had sex with FSW 79.59 percent of the participants used condom during last sexual contact with FSWs in Nepal whereas 20.41 percent of the participants had not used condom. About 27.27 percent of the participants had sexual contact with the male partner whereas $72.73 \%$ had reported never had sexual contact with male partners. $53.22 \%$ used condoms when having sexual contact with the male partners and 46.77 did not used condom.

Among total respondents, 23.7 percent migrants were at risk of HIV and 76.3 percent migrants did not at risk of HIV. The risk of HIV in age group distribution found that, age group of 26-35 years was found to be 3.40 times higher in risk than $36-45$ years. Similarly the risk of HIV was 4.643 times higher among age group 15-25 years as compared to $36-45$ years. Among them Disadvantage Dalit caste had more risk than Upper caste. Similarly illiterate had more risk than Literate. In distribution of risk of HIV unmarried had high than ever married.

\section{Conclusions}

The Study showed that seasonal migrants of Nepal have increased vulnerability to HIV. The unmarried labor worker and disadvantaged caste group were in the higher risk of facing HIV infection. It is necessary to design better service delivery focusing on these areas and need to explore the real situations of labor migrants.

\section{Keywords}

Risk of HIV; Seasonal Migrants; Terai Region

\section{Acknowledgments}

I thank to Office of family health International (FHI) and Department of Epidemioology and diseae control diviion of nepal that help to provide necessary information.

\section{References}

Integrated Biological and Behavioural Surveillance survey (IBBS) among seasonal migrants of western and mid to far western regions, 2008 , FHI/New Era.

Integrated Biological and Behavioural Surveillance survey 2002, FHI/ New Era, IBBS.

National Center for AIDS and STD Control 2007 national estimates of HIV.

Lowe D, Francis C 2006 protecting people on the move :applying lessons learned in Asia to improve HIV/AIDS interventions for mobile people. FHI

Poudel KC, Masamine J, Okumura J, Joshi AB, Wakai S. 2004. Migrants' risky sexual behaviours in India and at home in far western Nepal. "Tropical Medicine and International Health 9(8):897-903".

Poudel KC, Okumura J, Sherchand JB, Jimba M, Murakami I, Wakai S. 2003. Mumbai disease in far western Nepal: HIV infection and syphilis among male migrant-returnees and non-migrants. "Tropical Medicine and International Health 8(10):933-9".

\section{*Satya Narayan Yadav}

E-mail: satya.yd@gmail.com 